\title{
In Vitro Mutagenesis followed by Polymorphism Detection Using Start Codon Targeted Markers to Engineer Brown Spot Resistance in Kalanchoe
}

\author{
Rui Li ${ }^{1}$ \\ Chongqing Engineering Research Center for Floriculture, Key Laboratory of Horticulture Science for \\ Southern Mountainous Regions, Ministry of Education, College of Horticulture and Landscape \\ Architecture, Southwest University, Chongqing 400715, People's Republic of China \\ Lu Fan' \\ Lezhi Forestry Bureaus, Lezhi 641500, Sichuan, People's Republic of China \\ Jingdong Lin, Mingyang Li, Daofeng Liu ${ }^{2}$, and Shunzhao Sui ${ }^{2}$ \\ Chongqing Engineering Research Center for Floriculture, Key Laboratory of Horticulture Science for \\ Southern Mountainous Regions, Ministry of Education, College of Horticulture and Landscape \\ Architecture, Southwest University, Chongqing 400715, People's Republic of China
}

\begin{abstract}
AdDitional INDEX words. EMS, leaf spot, molecular marker, mutant, ornamental plants, SCoT
Abstract. Kalanchoe (Kalanchoe blossfeldiana) is a common potted flower that is popular throughout the world. Brown spot (caused by Stemphylium lycopersici) is one of the common foliage diseases in kalanchoe. This disease tends to infect leaves of kalanchoe plants in hot and humid environments, reducing their aesthetic value. The current investigation aimed to generate mutations resistant to brown spot in 'Mary' kalanchoe through chemical mutagenesis followed by molecular marker identification. Putative mutants were developed by treating embryogenic calluses with ethyl methanesulfonate (EMS) at median lethal doses (LD50)-either a $0.8 \%$ concentration for 2 hours or a $1.0 \%$ concentration for 0.5 hours. Brown spot crude toxin solution was used as the selection agent to identify diseaseresistant calluses during tissue culture. The optimal crude concentration $(60 \%)$ was determined by soaking calluses with different concentrations of crude pathogen: $0 \%, 20 \%, 40 \%, 60 \%$, and $80 \%$ (v/v). A total of 32 anti-brown spot lines were regenerated and tested for disease resistance with detached leaves. Three regenerated EMS mutant lines showed no obvious brown spot lesions on their leaves after the disease resistance assay and were subjected to polymorphism identification by start codon targeted (SCoT) molecular markers. Three (SCoT40, SCoT71, and SCoT72) of 45 selected primers were chosen to identify the mutants. This work may lay the foundation for further development of new disease-resistant cultivars of kalanchoe.
\end{abstract}

Kalanchoe, a member of the Crassulaceae family, mostly originated on the island of Madagascar in Africa (Smith, 2004). It is an important ornamental species often grown in containers and planted in commercial greenhouses (Yousefi and Soheily, 2014). Kalanchoe is popular throughout the world as a potted plant because of its colorful flowers and vibrant green leaves. Leaf spot is a type of fungal disease affecting the aerial portion of plants (Nasehi et al., 2014a), including the leaves and stems of different plants. It causes yield loss in vegetable crops (Nasehi et al., 2014b) and reduces ornamental value in ornamental plants. Kalanchoe plants are susceptible to leaf spot when cultivated in hot and high-humidity environments (Yao, 2014). Several studies have shown that the Stemphylium sp. was the common pathogen infecting Kalanchoe sp., causing leaf spot (Kwon et al., 2007; Shen et al., 2012; Yao, 2014). Leaf spot with classic symptoms on the leaves of kalanchoe was observed at Chongqing in southwest China, where the summer

Received for publication 22 Oct. 2018. Accepted for publication 1 Apr. 2019. This research was financially supported by the Chongqing Municipal Education Project, China (grant no. CY140206); and the Chongqing Research Program of Basic Research and Frontier Technology (no. cstc2016jcyjA0153).

${ }^{1}$ These authors contributed equally to this work.

2Corresponding authors. E-mail: Liu19830222@163.com or sszcq@swu. edu.cn. climate is hot and humid. This leaf spot was identified as brown spot in our previous work (Fan, 2015).

Breeding new disease-resistant cultivars is one of the most economical ways to avoid or reduce infection, in addition to being effective and direct (Vales et al., 2018). In addition, exploiting genetic variations is a prerequisite for plant breeders to breed new cultivars with better characteristics, such as resistance to various environmental stressors, pests, and diseases, along with increased yield and quality ( $\mathrm{Gu}$ et al., 2003; Maluszynski et al., 1995). Because the occurrence of spontaneous mutations is very low under natural conditions, we must undertake other measures to generate variation. For this reason, mutational techniques have been fully applied in plant breeding to create profitable cultivars of crops with good traits (Maluszynski et al., 1995).

Tissue culture technology contributes significantly to modern ornamental plant breeding ( $\mathrm{Fu}, 2017)$. It can preserve elite resources and provide production for genetic manipulation system, such as haploidization, polyploidization, and mutation breeding (Rego and de Faria, 2001). In addition, mutation breeding during tissue culture can combine with in vitro selection and increase breeding efficiency significantly (Cassells, 2002). It has been reported that in vitro mutagenesis with a combination of tissue culture techniques is one method for improving plant quality (Arène et al., 2007) and disease

J. Amer. Soc. Hort. SCI. 144(3):193-200. 2019. 
resistance (Ge et al., 2015) with high feasibility and high availability.

EMS is a conventional chemical mutagen that can produce many gene mutations (point mutations) with few chromosomal disruptions (Perera et al., 2015). EMS can be used easily for the mutagenesis of plants and has been used successfully to assist in the breeding of plants such as soybean (Glycine max), chrysanthemum (Dendranthema grandiflora), and tomato (Solanum lycopersicum) (Fang and Traore, 2011; Hofmann et al., 2004; Latado et al., 2004; Watanabe et al., 2007). After mutagenesis, crude toxins isolated from infected plants are added into a medium for selection to obtain disease-resistant resources, a process that has been well-developed (Liang et al., 2013; Liu et al., 2016a).

A large number of target populations can be developed by mutation induction (Wani et al., 2014). Breeders can use them for plant artificial selection to breed new cultivars (Wani et al., 2014). To breed new cultivars more efficiently, it is desirable to combine some molecular biology techniques after mutagenesis, with molecular markers being the most widely used and simplest approach (Wani et al., 2014). Molecular markers are specific DNA fragments that can represent differences at the genomic level. Such differences may correspond to changes in the phenotype of a plant and, therefore, can be used as tools to detect alterations at the DNA level. SCoT markers, developed in 2008, are DNA molecular markers based on single primers designed from the short conserved region flanking the ATG start codon in plant genes (Collard and Mackill, 2009). Collard and Mackill (2009) found that SCoT primers can amplify marker bands as random amplified polymorphic DNA (RAPD) markers and used rice to verify that this method facilitates genetic analysis, population segregation analysis, and quantitative trait locus detection (Collard and Mackill, 2009). Since then, SCoT primers have been used to generate DNA markers in different plant species (Fan et al., 2016; Li et al., 2013; Liu et al., 2016b).

In this study, we aimed to obtain mutant plants of kalanchoe resistant to brown spot by EMS mutagenesis combined with the SCoT molecular marker for identification, offering the possibility of applying this protocol to gain commercially suitable materials of kalanchoe resistant to Stemphylium lycopersici.

\section{Materials and Methods}

Callus induction. 'Mary' kalanchoe preserved by the Chongqing Engineering Research Center for Floriculture was used in all experiments. For callus induction, healthy young leaves were collected. The leaves were surface-disinfested in a $0.1 \%$ corrosive sublimate solution for 3 to $5 \mathrm{~min}$ and rinsed four times with sterile deionized water. The sterilized leaf explants were dissected $(1 \times 1 \mathrm{~mm})$ and inoculated on callus induction medium: Murashige and Skoog (MS) basal medium (Murashige and Skoog, 1962) supplemented with $6 \mathrm{mg} \cdot \mathrm{L}^{-1}$ 6-benzylaminopurine (6-BA) and $0.2 \mathrm{mg} \cdot \mathrm{L}^{-1} 1$-naphthylacetic acid (NAA) autoclaved at $121{ }^{\circ} \mathrm{C}$ for $20 \mathrm{~min}$. After growth for $20 \mathrm{~d}$ in an air-conditioned room under long-day conditions at $25 \pm 2{ }^{\circ} \mathrm{C}(16 / 8 \mathrm{~h}$ light/dark), the compact and green calluses were used for all subsequent experiments.

Poisoning EFFects AND OPTIMAL CONCENTRATION OF CRUDE TOXIN ON CALLUSES OF KALANCHOE. A crude toxin was prepared from the brown spot of $S$. lycopersici isolated from the diseased leaves (Fig. 1A). The brown spot strains were inoculated on autoclaved $\left(121{ }^{\circ} \mathrm{C}\right.$ for $\left.20 \mathrm{~min}\right)$ potato dextrose agar [PDA (Yang et al., 2017)] for $7 \mathrm{~d}$ at $25^{\circ} \mathrm{C}$. A colony with a diameter of $5 \mathrm{~mm}$ was transferred into $250-\mathrm{mL}$ flasks containing $100 \mathrm{~mL}$ potato dextrose culture medium and cultured with shaking at $100 \mathrm{rpm}$ in darkness at $25^{\circ} \mathrm{C}$. After $20 \mathrm{~d}$, the culture solution was filtered with a $0.75-\mu \mathrm{m}$ filter and centrifuged for $10 \mathrm{~min}$ at $900 g_{\mathrm{n}}$. The supernatant was concentrated as the $100 \%$ crude toxin and stored at $4{ }^{\circ} \mathrm{C}$.

Thirty leaf calluses $\left(0.5 \times 0.5 \mathrm{~cm}^{2}\right)$ from the 20 -d cultivation were cultured in medium containing the $100 \%$ crude toxin and shaken at $25{ }^{\circ} \mathrm{C}$ at $100 \mathrm{rpm}$. After $48 \mathrm{~h}$ of cultivation, the calluses were washed with disinfected water three or four times and subcultured on a successive culture medium (subculture medium), MS basal medium supplemented with 1.0 $\mathrm{mg} \cdot \mathrm{L}^{-1}$ 6-BA, $0.2 \mathrm{mg} \cdot \mathrm{L}^{-1} \mathrm{NAA}$, and $2.0 \mathrm{mg} \cdot \mathrm{L}^{-1}$ gibberellic acid $\left(\mathrm{GA}_{3}\right)$ for $20 \mathrm{~d}$. The optimum concentration of crude toxin for resistance screening was determined by transferring the sterilized calluses $\left(0.5 \times 0.5 \mathrm{~cm}^{2}\right)$ grown for $20 \mathrm{~d}$ to the subculture medium containing various concentrations of crude toxin: $0 \%, 20 \%, 40 \%, 60 \%$, and $80 \%(\mathrm{v} / \mathrm{v})$. Different concentrations of crude toxin were prepared with sterile water and crude toxin stock solution in the appropriate proportions. After cultivation for $20 \mathrm{~d}$, the callus differentiation rate was quantitated. Each treatment was administered to 30 calluses and repeated three times:

$$
\begin{aligned}
& \text { Differentiation rate of calluses }(\%) \\
& \quad=\frac{\text { No. of differentiated leaf calluses }}{\text { Total no. of leaf calluses }} \times 100 .
\end{aligned}
$$

OPTIMUM EMS DOSE AND TIME FOR KALANCHOE CALLUS TREATMENT. Leaf calluses $\left(0.5 \times 0.5 \mathrm{~cm}^{2}\right)$ grown for $20 \mathrm{~d}$ were inoculated into aqueous solutions containing $0.1 \%, 0.2 \%, 0.4 \%$, $0.8 \%, 1.0 \%$, and $1.2 \%(\mathrm{v} / \mathrm{v})$ EMS and shaken in an orbital shaker at $25{ }^{\circ} \mathrm{C}(100 \mathrm{rpm})$ for $0.5,1$, and $2 \mathrm{~h}$, respectively. Different volumes of EMS $(0,20,80,160,200$, and $240 \mu \mathrm{L})$ were added to $20 \mathrm{~mL}$ of $0.01 \mathrm{~mm}$ phosphate buffer $(\mathrm{pH} 7)$ to acquire the final treatments: $0.1 \%, 0.2 \%, 0.4 \%, 0.8 \%, 1.0 \%$, and $1.2 \%$. After EMS treatment, the calluses were rinsed five or six times and transferred to the subculture medium. The survival rate of calluses was analyzed and calculated after $20 \mathrm{~d}$ of cultivation. Each treatment was administered to 30 calluses and repeated three times. The LD50 was confirmed during the process:

Callus survival rate $(\%)=\frac{\text { No. of surviving leaf calluses }}{\text { Total no. of leaf calluses }} \times 100$.

Preparation of mutagenic Lines. Three groups of kalanchoe mutagenic lines were developed as show in Fig. 2A. The EMS mutagenesis group included the 50 kalanchoe calluses (grown for $20 \mathrm{~d}$ ) treated with EMS mutagenesis randomly by each LD50: a $0.8 \%$ concentration for $2 \mathrm{~h}$ or a $1.0 \%$ concentration for $0.5 \mathrm{~h}$ and cultured on the subculture medium for $20 \mathrm{~d}$. Then, well-grown calluses were transferred to the subculture medium with the addition of $60 \%$ crude toxin, for a $10-\mathrm{d}$ cultivation to screen anti-brown spot mutagenic lines. In addition, the crude toxin-induced group included the 50 kalanchoe calluses (grown for $20 \mathrm{~d}$ ) cultured on the subculture medium with $60 \%$ crude toxin for $30 \mathrm{~d}$ of cultivation to obtain anti-brown spot lines. The untreated group contained the calluses that did not undergo EMS mutagenesis or toxin crude induction, but grew on the subculture medium for $30 \mathrm{~d}$. All 

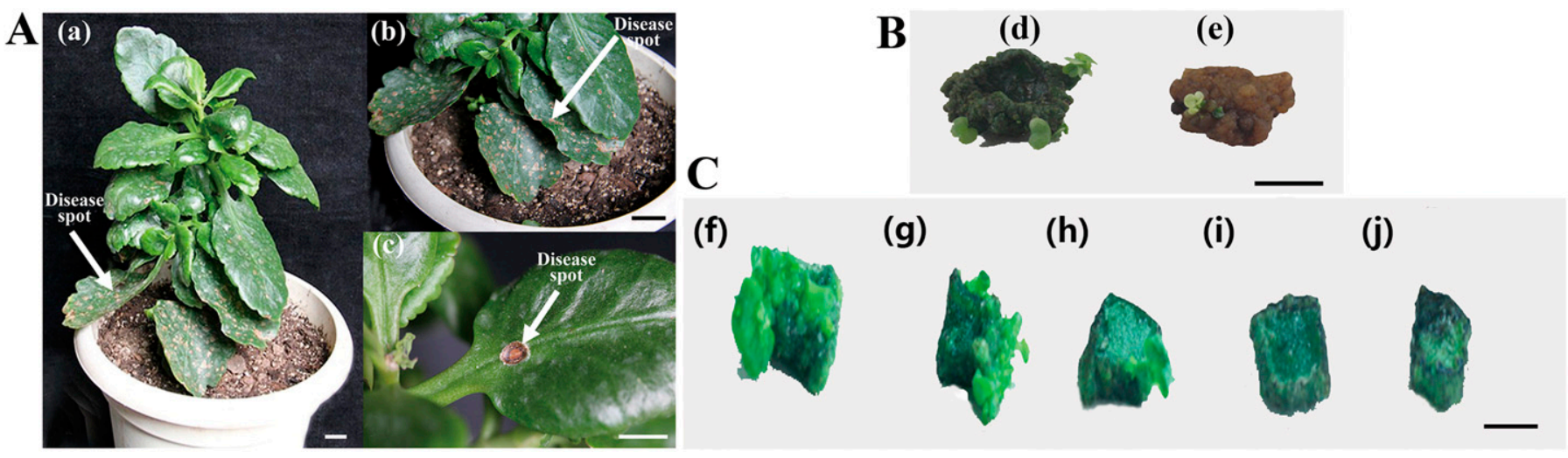

Fig. 1. Foliar symptoms on kalanchoe. (A) Brown spot was shown on the whole plant (a), partial leaves (b), and a single leaf (c). Toxic effect of crude toxin derived from Stemphylium lycopersici on kalanchoe calluses were photographed after $3 \mathrm{~d}$ of cultivation. (B) Calluses treated without crude toxins (d) and calluses treated with $100 \%$ crude toxins for $48 \mathrm{~h}(\mathbf{e})$. (C) Calluses treated with crude toxin at various concentrations for $48 \mathrm{~h}: 0 \%$ (f), $20 \%$ (g), $40 \%$ (h), 60\% (i), and $80 \%$ (j). Differentiation was observed after $20 \mathrm{~d}$; scale bars $=1 \mathrm{~cm}$.

adventitious buds were transferred to shoot-strengthening medium, MS basal medium supplemented with $1.0 \mathrm{mg} \cdot \mathrm{L}^{-1} 6-\mathrm{BA}, 0.2 \mathrm{mg} \cdot \mathrm{L}^{-1} \mathrm{NAA}$, and $2.0 \mathrm{mg} \cdot \mathrm{L}^{-1} \mathrm{GA}_{3}$, and rooted on rooting medium, $1 / 2$ MS basal medium supplemented with $0.5 \mathrm{mg} \cdot \mathrm{L}^{-1}$ 3 -indolebutyric acid and $0.5 \mathrm{mg} \cdot \mathrm{L}^{-1}$ NAA. Several mutagenic lines were obtained from the three groups, and some of them were transplanted to detect disease resistance.

DETECTION OF DISEASE RESISTANCE IN REGENERATED PLANTS. Resistance detection was performed with all regenerated plants from the three groups (Fig. 2A). Leaves of regenerated plants with petioles were used for detection. The $100 \%$ brown spot crude toxin was inoculated on the detached leaves for $5 \mathrm{~d}$. To keep leaves moist, the petioles were wrapped with a small amount of sterile cotton wool. Needles were used to create symmetric wounds on both sides of the leaves. Brown spot was inoculated on the wound with the same patch of pathogens on both sides of leaves. Two leaves were chosen at random from each plant to detect disease resistance of the mutagenic lines. The control plants were inoculated with the same size of blank PDA medium on wounds. The infected detached leaves were placed into a petri dish containing moist filter paper, covered with film, and put into a constanttemperature incubator at $25^{\circ} \mathrm{C}$. Disease resistance was evaluated by the disease index (DI) and relative resistance index (RRI) (Fu et al., 2015; Liu et al., 2005). The DI was evaluated based on the disease severity score of each plant, quantitated by visual assessment on a $0-9$ scale according to the pesticide field efficacy test criteria (Department of Agriculture Pesticide Testing Laboratory, 1993; Liu et al., 2005). Relative resistance levels were evaluated based on the RRI as follows (Fu et al., 2015):

$$
\mathrm{RRI}=\frac{(\text { DI of control plants }- \text { DI of mutation })}{\text { DI of control plants }} \times 100 .
$$

SCOT-POLYMERASE CHAIN REACTION (PCR) AMPLIFICATION. Young and healthy leaf tissues were collected for DNA extraction using the cetyltrimethylammonium bromide (CTAB) method (Scobeyeva et al., 2018). The DNA concentration was measured using a spectrophotometer (NanoDrop 
2000; Thermo Fisher Scientific, Waltham, MA), and DNA quality was verified by electrophoresis (DIY-6C; Liuyi Instrument Factory, Beijing, China) on a $1 \%$ agarose gel. DNA concentrations were adjusted to $50 \mathrm{ng} \cdot \mu \mathrm{L}^{-1}$, and DNA was stored at $-20{ }^{\circ} \mathrm{C}$ for the next experiment. The SCoT30-80 primers (Luo et al., 2010) were ordered from TsingKe (Chengdu, China). All primers were screened with wild-type kalanchoe materials for polymorphisms and reproducibility. After prescreening, the selected primers were used to identify putative mutants. Each amplification was performed using $20-\mu \mathrm{L}$ amplification reactions consisting of $2.0 \mathrm{mM} \mathrm{MgCl}_{2}$, $0.5 \mathrm{~mm}$ dNTP mixture, $0.4 \mathrm{~mm}$ primer, $60 \mathrm{ng}$ template DNA, and $0.20 \mathrm{U}$ polymerase. PCR was performed in a thermocycler (T3000; Biometra, Göttingen, Germany) as follows: initial denaturation at $94{ }^{\circ} \mathrm{C}$ for $5 \mathrm{~min}$, followed by 36 cycles of $94{ }^{\circ} \mathrm{C}$ for $60 \mathrm{~s}, 53{ }^{\circ} \mathrm{C}$ for $30 \mathrm{~s}, 72{ }^{\circ} \mathrm{C}$ for $120 \mathrm{~s}$, and a final extension held at $72{ }^{\circ} \mathrm{C}$ for $5 \mathrm{~min}$. The reaction products $(10 \mu \mathrm{L})$ were separated by $1.5 \%$ horizontal agarose gel electrophoresis in trisboric acid-disodium ethylenediaminetetraacetic acid buffer. DNA marker sets of 500 to $2000 \mathrm{bp}$ and 1000 to $15,000 \mathrm{bp}$ were used to compare the DNA band lengths of amplified products. The gels were stained with $0.1 \mathrm{~g} \cdot \mathrm{mL}^{-1}$ nucleic acid stain (GoldView; Solarbio Science \& Technology, Beijing, China) and scanned using an image system (Gel BioDoc 2000; Bio-Rad, Hercules, CA). The number of bands produced by each primer and the frequencies of polymorphisms were calculated separately.

Data ANalysis. The differentiation rate of calluses treated with various concentrations of crude toxin was subjected to analysis of variance. Each treatment was replicate three times. IBM SPSS software (version 22.0; IBM Corporation, Armonk, NY) was used to illustrate traditional analysis. Mean differences of each group were compared by Duncan's multiple range test (MRT) at $P<0.05$. After that, the optimal concentration of crude toxin for selection was determined.

\section{Results}

Poisoning efFects AND SElection of the optimal CONCENTRATION OF CRUDE TOXIN ON KALANCHOE CALLUSES. The brown spot-infected kalanchoe plant is shown in Fig. 1A. After the toxic effect test of the crude toxin, the calluses turned brown on their surface and their differentiation and regeneration were affected (Fig. 1B). The callus differentiation rate after $20 \mathrm{~d}$ was reduced effectively, with increasing crude toxin concentrations from $20 \%, 40 \%, 60 \%$, and $80 \%$ (Table 1). The highest callus differentiation rate was in the control group ( $0 \%$ crude toxin), reaching $94.44 \%$. When using $20 \%$ crude toxin, the differentiation rate of callus decreased to $87.78 \%$ (Table 1), and the calluses showed no differences compared with the control group (Fig. 1C). When using $40 \%$ crude toxin, the callus differentiation rate was $61.11 \%$ (Table 1), and the calluses started to brown (Fig. 1C). When using $60 \%$ crude toxin, more than half the calluses turned brown and $\approx 26.66 \%$ of calluses were differentiated (Table 1), which may represent a functional trait for a selection process. When using $80 \%$ crude toxin, the differentiation rate of the calluses was $12.22 \%$ (Table 1), and most calluses had difficulty differentiating into shoots and ultimately died (Fig. 1C). Therefore, the $60 \%$ concentration could be used as an effective critical concentration for crude toxin screening.

OPtiMuM EMS dOSE AND TIME FOR KaLANChOE CALLUSES. After treating calluses with various EMS concentrations for different durations of time, the callus survival rate decreased with an increase in the EMS concentration and showed similar trends among different concentrations at different time durations. The survival rate decreased from $97 \%$ with $0.1 \%$ EMS treatment to $10 \%$ with $1.2 \%$ EMS treatment; treating with $1.2 \%$ EMS showed the greatest mortality (Table 2). One hour of treatment with $0.8 \%$ EMS and $2 \mathrm{~h}$ of treatment with $1.0 \%$ EMS both produced callus survival rates of $\approx 50 \%$ (Table 2). Based on these results, LD50 was a concentration of $0.8 \%$ for $2 \mathrm{~h}$ or a concentration of $1.0 \%$ for $0.5 \mathrm{~h}$.

IDENTIFICATION OF REgENERATED PLANTS WITH DISEASE RESISTANCE. About 35 putative tolerant plantlets were regenerated and assessed by resistance detection in vitro: 22 in the EMS mutagenesis group (Table 2) and 13 in the crude toxin-induced group (Table 1). And 20 untreated plants were also carried out the resistance detection as the control group (Table 1). The results showed that leaves from the regenerated plants started to turn yellow $48 \mathrm{~h}$ after inoculation, and classic brown spots appeared on the leaves after $3 \mathrm{~d}$. Five days later, severity scores of the plants tested for disease resistance were obtained by visual assessment and counted for DI and RRI. Compared with the untreated and crude toxin-induced plants, the EMS-mutagenized plants displayed significantly different symptoms on the leaf

Table 1. After treating with brown spot crude toxin of Stemphylium lycopersici at various concentrations, the differentiation rate and growth state of kalanchoe calluses were recorded. Treating calluses with $0 \%$ and $60 \%$ crude toxin could get the untreated and crude toxin-induced plants, respectively. One-month-old shooting plants were performed resistance detection, and evaluated their resistance through disease index (DI) and relative resistance index (RRI).

\begin{tabular}{|c|c|c|c|c|c|c|c|}
\hline \multirow{2}{*}{$\begin{array}{l}\text { Crude toxin } \\
\text { concn }(\%)\end{array}$} & \multirow{2}{*}{$\begin{array}{l}\text { No. of } \\
\text { treated calluses }\end{array}$} & \multirow{2}{*}{$\begin{array}{c}\text { Differentiation } \\
\text { rate }[\text { mean } \pm \mathrm{SD}(\%)]\end{array}$} & \multirow[b]{2}{*}{ Growth state ${ }^{\mathrm{z}}$} & \multirow{2}{*}{$\begin{array}{l}\text { No. of treated } \\
\text { calluses for } \\
\text { mutagenic lines }\end{array}$} & \multirow{2}{*}{$\begin{array}{l}\text { Shooting } \\
\text { (no.) }\end{array}$} & \multicolumn{2}{|c|}{ Resistance } \\
\hline & & & & & & $\overline{\mathrm{DI}(\%)}$ & $\overline{\text { RRI }(\%)}$ \\
\hline 0 & 90 & $94.44 \pm 5.09 \mathrm{a}^{\mathrm{y}}$ & ++++ & 50 & 20 & 50.62 & $0.00(\mathrm{HS})$ \\
\hline 40 & 90 & $61.11 \pm 5.09 \mathrm{c}$ & +++ & - & - & - & - \\
\hline 60 & 90 & $26.66 \pm 5.77 \mathrm{~d}$ & + & 50 & 13 & 42.48 & $23.53(\mathrm{~S})$ \\
\hline 80 & 90 & $12.22 \pm 3.85 \mathrm{~d}$ & + & - & - & - & - \\
\hline
\end{tabular}

$\overline{\mathrm{z}_{++++}}=$best growth state of calluses and high adventitious bud differentiation; $+++=$normal growth state of calluses and some browned calluses; + = poor growth state of calluses and most calluses seriously browned.

${ }^{\mathrm{y}}$ Each treatment was replicated three times. Mean separation in columns by Duncan's multiple range tests at $P \leq 0.05$.

${ }^{\mathrm{x}}$ No individuals.

$\mathrm{HS}=$ high susceptibility to brown spot disease; $\mathrm{S}=$ susceptibility to brown spot disease. 
Table 2. Survival rate of kalanchoe calluses after different concentrations and durations of ethyl methanesulfonate (EMS) treatment were calculated. The median lethal doses (LD50s) of EMS treatment were used to get anti-brown spot lines. One-month-old shooting anti-brown spot lines were performed resistance detection, and evaluated their resistance through disease index (DI) and relative resistance index (RRI).

\begin{tabular}{|c|c|c|c|c|c|c|}
\hline \multicolumn{2}{|c|}{ EMS treatment } & $\begin{array}{c}\text { Survival } \\
(\%)^{\mathrm{x}}\end{array}$ & $\begin{array}{c}\text { No. of treated } \\
\text { calluses for } \\
\text { mutagenic lines }\end{array}$ & $\begin{array}{c}\text { No. of } \\
\text { shooting } \\
\text { plants }\end{array}$ & \multicolumn{2}{|c|}{ Resistance } \\
\hline \multirow[t]{2}{*}{0.1} & 0.5 & 97 & $-^{\mathrm{v}}$ & - & - & - \\
\hline & 2.0 & 90 & & & & \\
\hline \multirow[t]{2}{*}{0.2} & 0.5 & 89 & - & - & - & - \\
\hline & 1.0 & 83 & & & & \\
\hline & 1.0 & 75 & & & & \\
\hline & 2.0 & 62 & & & & \\
\hline \multirow[t]{3}{*}{0.8} & 0.5 & 77 & & 22 & 31.83 & \\
\hline & 1.0 & 69 & & & & 42.70 (MR) \\
\hline & 2.0 & 56 & 50 & & & \\
\hline \multirow{2}{*}{1.2} & 1.0 & 24 & & & & \\
\hline & 2.0 & 10 & & & & \\
\hline
\end{tabular}

${ }^{\mathrm{z}}$ Numbers in bold type indicate concentration of LD50s in the EMS treatment.

${ }^{\mathrm{y}}$ Numbers in bold type indicate the duration of LD50s in the EMS treatment.

${ }^{\mathrm{x}}$ Numbers in bold type indicate the survival rate of LD50s in the EMS treatment.

${ }^{\mathrm{w}}$ The LD50 value used to obtain the mutagenic lines was selected randomly from the two LD50s.

${ }^{\mathrm{v}}$ No individuals.

$\mathrm{MR}=$ medium resistance to brown spot disease.

surface after crude toxin inoculation (Fig. 2B), and data show that the EMS-mutagenized plants had the greatest RRI, reaching $42.70 \%$ (Table 2). According to the RRI, it was concluded that EMS-mutagenized plants showed medium resistance against brown spot disease in our experiment (Table 2), whereas the untreated plants showed a high susceptibility and the crude toxininduced plants showed susceptibility resistance against brown spot disease (Table 1). Three EMS mutant lines were selected for DNA marker identification with no obvious crude toxin lesions on their leaves and the lowest severity score in the plants tested for disease resistance (a value of three).

Detection of putative mutants by SCoT-PCR AMPLIFICATION. The three EMS mutant lines with greater resistance were assessed using SCoT markers (Fig. 3B). A total of 45 primers were used initially for primer selection by wild-type kalanchoe, and 14 primers showing bands from 3 to 11 were selected from the prescreening. Seven primersSCoT34, SCoT38, SCoT40, SCoT65, SCoT67, SCoT71, and SCoT72-were used separately for marker amplification between wild-type and EMS mutant lines according to the numbers they amplified (Table 3). Finally, only three primers-SCoT40, SCoT71, and SCoT72-produced stable, clear-cut polymorphic bands and were selected to identify wildtype and three EMS mutant lines of kalanchoe (Fig. 3B). A total of 40 bands were amplified with the three primers, including bands from wild-type kalanchoe and three EMS mutant lines (Table 3). In addition, an average of 13.3 bands was amplified with each primer, ranging from 12 to 15 bands, of which 18 polymorphic bands in total showed that the average polymorphism rate was $45 \%$ (Table 3 ).

\section{Discussion}

EMS is a mutagen used widely to induce mutations in plants, but its application to kalanchoe has not yet been reported. Embryogenic callus is an ideal material for mass mutation induction, especially for EMS mutagenesis and directed selection during plant tissue culture (Predieri, 2001). Previously, numerous studies established a well-developed regeneration system for $K$. blossfeldiana. This system provided prerequisites for the in vitro mutagenesis and pressure selection of calluses (Chen et al., 2004a, 2004b; Cheng et al., 2009). In our study, kalanchoe calluses were subjected to EMS treatment to obtain EMS mutant lines.

LD50 is a safe dose at which $50 \%$ of calluses can survive during EMS mutagenesis (Roslim et al., 2015). Mutagenesis by LD50s of EMS can produce maximum mutations with minimum hazards (Wani et al., 2014). LD50 needs to be determined before in vitro mutagenesis because the value can differ between cultivars and explants, including tissues and organs (Bhagwat and Duncan, 1998; Ge et al., 2015). In giant miscanthus (Miscanthus xgiganteus), specific explants were treated with individual LD50s of EMS. When inflorescences were used as explants with EMS treatment, the LD50 dose was $0.6 \%$ EMS for $90 \mathrm{~min}$. However, when using calluses as explants, the LD50 dose was $1.2 \%$ EMS for 90 min (Perera et al., 2015). When EMS was applied to treat tomato seeds, the LD50 dose was $0.5 \%$ EMS for $48 \mathrm{~h}$ (Watanabe et al., 2007). In our study, we explored EMS concentrations and duration time to determine LD50s for callus treatment and found that there were two suitable LD50s for kalanchoe mutagenesis: $0.8 \%$ for $2 \mathrm{~h}$ or $1.0 \%$ for $0.5 \mathrm{~h}$ (Table 2 ). 
After EMS mutagenesis, in vitro selection in culture medium can achieve targeted screening effectively, which is applicable for the isolation of mutants or induced cell lines (Ge et al., 2015; Luan et al., 2007). Efficient selection is beneficial for trialing cost reductions (Cassells, 2002). This process would improve the selection of somaclones tolerant to brown spot during tissue culture. According to a previous report, crude toxin could be a selection agent by adding it directly to a selection medium for disease-resistant plants (Ali et al., 2007). For example, to obtain sweet orange (Citrus sinensis) resistant to Xanthomonas citri ssp. citri $(X c c), X c c$-tolerant mutants were selected on liquid MT medium containing 10\% Xcc crude extract after EMS mutagenesis of sweet orange embryogenic calluses (Ge et al., 2015). The type and pressure of the selection agent are important determinants during this procedure (Van den Bulk, 1991). Although the leaf spot pathogen $S$. lycopersici has been identified from kalanchoe in Korea (Kwon et al., 2007), it has not been reported as a selected agent during culture tissue, let alone the selected concentration. Therefore, in this study, we confirmed the optimal concentration of crude toxin for selection during culture tissue and the poisoning effects of the brown spot crude toxin on calluses. The results show that the brown spot crude toxin produced by $S$. lycopersici was effective in distinguishing susceptible and tolerant genotypes of kalanchoe, and adding $60 \%$ brown spot crude toxin to the subculture medium could obtain brown spot-resistant calluses. Finally, a total of 32 induced anti-brown spot lines were regenerated and used for further analysis.

Although in vitro selection and in vivo resistance/sensitivity are correlated strongly (Flores et al., 2012), previous research has shown that disease resistance at the early stage did not mean the plants obtained significant resistance (Toyoda et al., 1989).
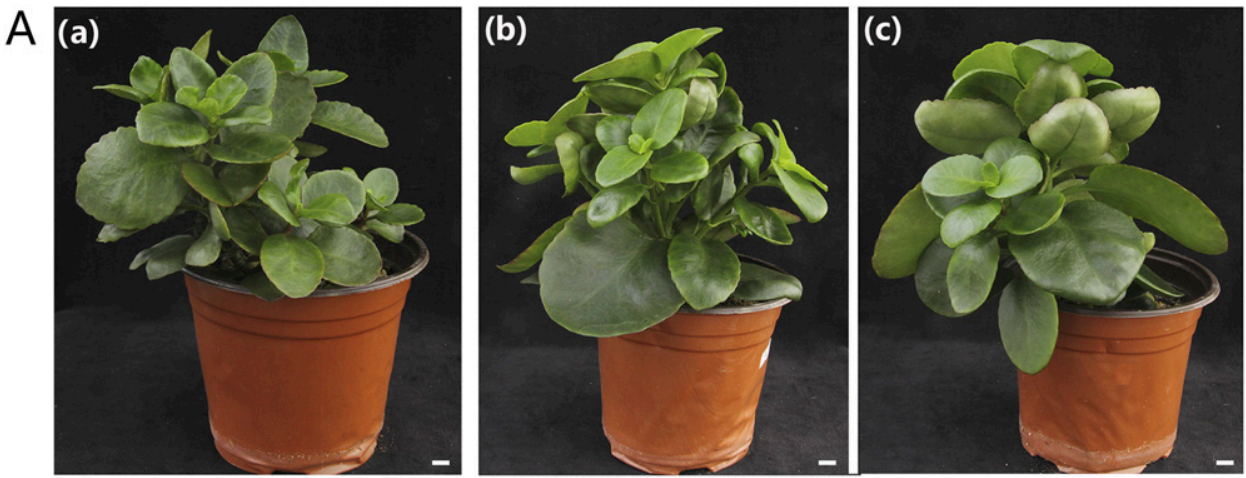

B
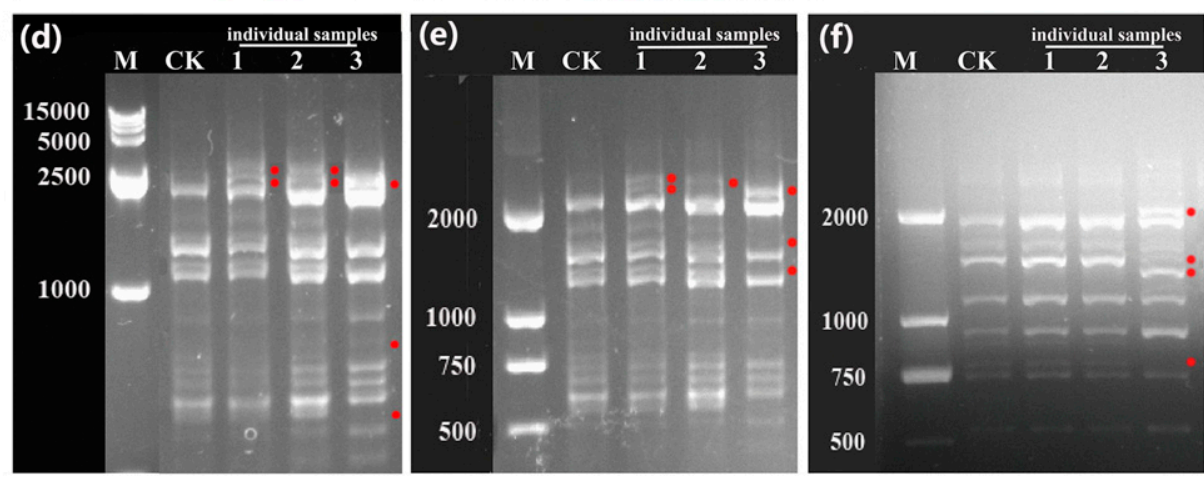

Fig. 3. (A) Three ethyl methanesulfonate (EMS) mutant lines of kalanchoe with brown spot resistance grown for 2 months: (a) 1, (b) 2, and (c) and 3, respectively. (B) Start codon targeted (SCoT)-polymerase chain reaction amplification of the three EMS mutant lines with three primers: (d) SCoT40, (e) SCoT71, and (f) SCoT72, respectively. Dots refer to band placement within the gel. DNA markers of 500 to $2000 \mathrm{bp}$ (e and f) and 1000 to $15,000 \mathrm{bp}(\mathbf{d})$ were used to compare the DNA band. $\mathrm{M}=$ DNA marker; $\mathrm{CK}=$ untreated; scale bars $=1 \mathrm{~cm}$.
Therefore, the anti-brown spot lines had to be verified further for brown spot resistance using in vitro assays. In our study, detached leaves were inoculated with a bacterial pathogen to identify disease resistance-an approach that has been used frequently in previous work (Chawla and Wenzel, 1987; Ge et al., 2015; $\mathrm{Xu}$ et al., 2007). Three regenerated plants exhibited activity against the disease according to the disease resistance assay.

Molecular markers are regarded as useful tools for the detection and analysis of genetic variations in plants. Identifying the difference with molecular markers between a mutant and its parents has been shown to be indispensable (Agarwal et al., 2008). Currently, many types of molecular markers are used for genetic diversity analysis in plants, and each marker system has certain advantages and disadvantages. Compared with several common molecular markers, including RAPD (Williams et al., 1990), intersimple sequence repeat markers [ISSR (Blair et al., 1999)] and amplified fragment length polymorphism markers, [AFLP (Vos et al., 1995)]

Table 3. Number of total amplification and polymorphic bands from seven prescreening start codon targeted (SCoT) primers amplified in three ethyl methanesulfonate mutant lines.

\begin{tabular}{llccc}
\hline SCoT primer no. & Primer sequence $\left(5^{\prime}-3^{\prime}\right)$ & No. of total bands & No. of polymorphic bands & Polymorphism $(\%)$ \\
\hline 34 & ACCATGGCTACCACCGCA & 7 & - - $^{z}$ \\
38 & CAATGGCTACCACTAACG & 10 & 5 & - \\
40 & CAATGGCTACCACTACAG & 13 & - \\
65 & ACCATGGCTACCACGGCA & 10 & 8.46 \\
67 & ACCATGGCTACCAGCGGC & 7 & 5 \\
71 & CCATGGCTACCACCGCCG & 15 & 53.33 \\
72 & CCATGGCTACCACCGCCC & 12 & 41.67 \\
\hline
\end{tabular}

${ }_{\mathrm{z}}$ No individuals. 
SCoT molecular markers may be superior. In rice, PCR amplification results with SCoT markers were generally more reproducible than RAPD marker results (Collard and Mackill, 2009). Furthermore, SCoT marker polymorphisms were shown to represent better the actual relationships among mango cultivars than ISSR markers (Luo et al., 2010). In addition, research on potato (Solanum tuberosum) indicated SCoT markers were more effective in detecting somatic clonal variation than two other types of molecular markers-specifically, ISSR and RAPD markers (Gorji et al., 2011). Therefore, we selected SCoT markers to identify the three brown spot-resistant plants. Our results show that SCoT markers were suitable for mutant identification in kalanchoe and can distinguish mutants successfully from their parents. Apparently, SCoT40, SCoT71, and SCoT72 may serve as specific markers for the marker-assisted selection of leaf-spot disease resistance when EMS mutants of kalanchoe are used as breeding materials. Our results also provide a useful reference for further research of kalanchoe and other Crassulaceae family plants.

Three EMS mutant lines were ultimately verified by a disease resistance test and SCOT molecular markers. Although only three mutant lines were obtained in our study, it is notable that this system is applicable to mutation breeding of kalanchoe. A feature of mutation breeding is that it can recur, and even the same gene in a plant can be induced after rounds of mutagenesis (Wani et al., 2014). This recurrence makes this system beneficial for the production of greater numbers of disease-resistant mutants.

In conclusion, an efficient protocol for in vitro EMS mutagenesis and selection of kalanchoe somaclones tolerant to brown spot was established. This protocol can be used to conduct a large-scale experiment to generate an abundance of brown spot-resistant resources. The selected putative mutants were verified by an in vivo assay for tolerance to brown spot and SCoT molecular markers. We produced several brown spotresistant mutants using this procedure and tested them under field conditions to screen for commercially suitable cultivars that could be applied extensively in landscaping.

\section{Literature Cited}

Agarwal, M., N. Shrivastava, and H. Padh. 2008. Advances in molecular marker techniques and their applications in plant sciences. Plant Cell Rpt. 27:617-631.

Ali, A., S. Naz, S.S. Alam, and J. Iqbal. 2007. In vitro induced mutation for screening of red rot (Colletotrichum falcatum) resistance in sugarcane (Saccharum officinarum). Pak. J. Bot. 39:1979-1994.

Arène, L., V. Bellenot-Kapusta, J. Belin, A. Cadic, M. Clérac, L. Decourtye, and M. Duron. 2007. Breeding program on woody ornamental plants in Angers-France: A collaboration of 32 years between INRA and SAPHO. Acta Hort. 734:35-38.

Bhagwat, B. and E.J. Duncan. 1998. Mutation breeding of banana cv. Highgate (Musa spp., AAA Group) for tolerance to Fusarium oxysporum f. sp. cubense using chemical mutagens. Scientia Hort. 73:11-22.

Blair, M.W., O. Panaud, and S.R. McCouch. 1999. Inter-simple sequence repeat (ISSR) amplification for analysis of microsatellite motif frequency and fingerprinting in rice (Oryza sativa L.). Theor. Appl. Genet. 98:780-792.

Cassells, A.C. 2002. Tissue culture for ornamental breeding, p. 139153. In: A. Vainstein (ed.). Breeding for ornamentals: Classical and molecular approaches. Kluwer, Dordrecht, Netherlands.

Chawla, H.S. and G. Wenzel. 1987. In vitro selection for fusaric acid resistant barley plants. Plant Breeding 99:159-163.
Chen, C., G. Wang, L. Tian, and R. Cui. 2004a. Embryoid induction and regeneration in callus of Kalanchoe blossfeldiana. Acta Hort. Sinica 31:249-252 (in Chinese).

Chen, Y., X. Zhi, Y. Zhang, and Z. Zhang. 2004b. Isolation leaf disks culture and high efficient plantlet regeneration of Kalanchoe blossfeldiana. Chinese Agr. Sci. Bul. 20:33-34 (in Chinese).

Cheng, J., C.M. Liu, J. Yuan, and X. Zhao. 2009. A kind of experimental material suitable for plant tissue culture: Kalanchoe blossfeldiana. J. Jilin Normal Univ. 30(4):121-122 (in Chinese).

Collard, B.C.Y. and D.J. Mackill. 2009. Start codon targeted (SCoT) polymorphism: A simple, novel DNA marker technique for generating gene-targeted markers in plants. Plant Mol. Biol. Rpt. 27:8693.

Department of Agriculture Pesticide Testing Laboratory. 1993. Guidelines for field efficacy trials of pesticides (1). China Standards Press, Beijing, China.

Fan, L. 2015. Research on isolation and identification of Kalanchoe brwon spot and in vitro screening of mutant resistant to pathogen. Southwest Univ., Chongqing, China, Master. Abstr. 1-46.

Fan, Z., L. Wang, D. Yang, D. Cao, Y. Yu, and Y. Zhang. 2016. Establishing the regeneration system for double-flowered Kalanchoe blossfeldiana. J. Northeast For. Univ. 44:54-58 (in Chinese).

Fang, J.Y. and S. Traore. 2011. In vitro mutation induction of Saintpaulia using ethyl methanesulfonate. HortScience 46:981-984.

Flores, P.S., W.C. Otoni, O.D. Dhingra, T.M.D. Santos, and C.H. Bruckner. 2012. In vitro selection of yellow passion fruit genotypes for resistance to Fusarium vascular wilt. Plant Cell Tissue Organ Cult. 108:37-45.

Fu, Y.F. 2017. Research progress on tissue culture and breeding of ornamental plants in China. J. Hebei For. Sci. Technol. 4:42-47 (in Chinese).

Fu, J., J. Cui, R. Zhou, X. Zhe, and J. He. 2015. Identification of resistance of major peanut cultivars (lines) to early leaf spot and web blotch in Liaoning Province. Plant Protection 41(1):171-173 (in Chinese).

Ge, H., Y. Li, H. Fu, G. Long, L. Luo, R. Li, and Z. Deng. 2015. Production of sweet orange somaclones tolerant to citrus canker disease by in vitro mutagenesis with EMS. Plant Cell Tissue Organ Cult. 123:29-38.

Gorji, A.M., P. Poczai, Z. Polgar, and J. Taller. 2011. Efficiency of arbitrarily amplified dominant markers (SCOT, ISSR and RAPD) for diagnostic fingerprinting in tetraploid potato. Amer. J. Potato Res. 88:226-237.

Gu, H.H., W.J. Zhou, and P. Hagberg. 2003. High frequency spontaneous production of doubled haploid plants in microspore cultures of Brassica rapa ssp. chinensis. Euphytica 134:239-245.

Hofmann, N.E., R. Raja, R.L. Nelson, and S.S. Korban. 2004. Mutagenesis of embryogenic cultures of soybean and detecting polymorphisms using RAPD markers. Biol. Plant. 48:173-177.

Kwon, J.-H., B.-R. Jeong, J.-G. Yun, and S.-W. Lee. 2007. Leaf spot of kalanchoe (Kalanchoe blossfeldiana) caused by Stemphylium lycopersici. Res. Plant Dis. 13:122-125 (in Korean).

Latado, R.R., A.H. Adames, and A.T. Neto. 2004. In vitro mutation of chrysanthemum (Dendranthema grandiflora Tzvelev) with ethylmethanesulphonate (EMS) in immature floral pedicels. Plant Cell Tissue Organ Cult. 77:103-106.

Li, P.R., J.F. Jiang, S.M. Chen, Z.Y. Guan, Y. Liao, W.M. Fang, and F.D. Chen. 2013. Establishment and optimization of SCoT molecular marker system in chrysanthemum and its application of analysis on genetic diversity. Acta Hort. Sinica 40:2015-2025 (in Chinese).

Liang, X.X., P. Li, and A.P. Zheng. 2013. In vitro selection of sheath blight resistance germplasms in rice. Afr. J. Microbiol. Res. 7:44224429.

Liu, Y., M. Chi, B.X. Wang, Z.Q. Song, B.G. Lu, J. Li, D.R. Qin, and D.Y. Xu. 2016a. Anti-blast mutant screened from tissue cultured with crude toxin from Pyricularia oryzae. Southwest China J. Agr. Sci. 29:2016-2019 (in Chinese). 
Liu, N., C. Guo, Y. Sun, H. Yu, L. Ma, and Z. Wu. 2016 b. Establishment and optimization of SCoT-PCR system in sugarbeet. Chinese Agr. Sci. Bul. 32:119-122 (in Chinese).

Liu, S., H. Wang, J. Zhang, B.D.L. Fitt, Z. Xu, N. Evans, Y. Liu, W. Yang, and X. Guo. 2005. In vitro mutation and selection of doubledhaploid Brassica napus lines with improved resistance to Sclerotinia sclerotiorum. Plant Cell Rpt. 24:133-144.

Luan, Y.S., J. Zhang, X.R. Gao, and L.J. An. 2007. Mutation induced by ethylmethanesulphonate (EMS), in vitro screening for salt tolerance and plant regeneration of sweet potato (Ipomoea batatas L.). Plant Cell Tissue Organ Cult. 88:77-81.

Luo, C., X.H. He, H. Chen, S.J. Ou, and M.P. Gao. 2010. Analysis of diversity and relationships among mango cultivars using start codon targeted (SCoT) markers. Biochem. Syst. Ecol. 38:1176-1184.

Maluszynski, M., B.S. Ahloowalia, and B. Sigurbjörnsson. 1995. Application of in vivo and in vitro mutation techniques for crop improvement. Euphytica 85:303-315.

Murashige, T. and F. Skoog. 1962. A revised medium for rapid growth and bio assays with tobacco tissue cultures. Physiol. Plant. 15:473497.

Nasehi, A., J.B. Kadir, M.N. Esfahani, F. Mahmodi, E. Golkhandan, S. Akter, and H. Ghadirian. 2014a. Cultural and physiological characteristics of causing leaf blight disease on vegetable crops. Arch. Phytopathol. Plant Protection 47:1658-1665.

Nasehi, A., J.B. Kadir, M. Nasr-Esfahani, F. Abed-Ashtiani, M.Y. Wong, S.K. Rambe, and E. Golkhandan. 2014b. Analysis of genetic and virulence variability of Stemphylium lycopersici associated with leaf spot of vegetable crops. Eur. J. Plant Pathol. 140:261-273.

Perera, D., D.J. Barnes, B.S. Baldwin, and N.A. Reichert. 2015. Mutagenesis of in vitro cultures of Miscanthus $\times$ giganteus cultivar Freedom and detecting polymorphisms of regenerated plants using ISSR markers. Ind. Crops Prod. 65:110-116.

Predieri, S. 2001. Mutation induction and tissue culture in improving fruits. Plant Cell Tissue Organ Cult. 64:185-210.

Rego, L.D.V. and R.T. de Faria. 2001. Tissue culture in ornamental plant breeding: A review. Crop Breeding Appl. Biotechnol. 1:283300 .

Roslim, D.I., Herman, and I. Fiatin. 2015. Lethal dose $50\left(\mathrm{LD}_{50}\right)$ of mungbean (Vigna radiata L. Wilczek) cultivar Kampar. SABRAO J. Breeding Genet. 47:510-516.

Scobeyeva, V.A., D.O. Omelchenko, L.M. Dyakov, A.S. Konovalov, A.S. Speranskaya, and A.A. Krinitsina. 2018. Comparison of some plant DNA extraction methods. Russ. J. Genet. 54:576-586.
Shen, Y.M., Y.C. Yang, Y.J. Fu, and T.H. Hung. 2012. First report of Stemphylium solani causing leaf spot of Kalanchoe blossfeldiana in Taiwan. New Dis. Rpt. 25:10 (in Taiwanese).

Smith, G. 2004. Kalanchoe species poisoning in pets. Vet. Med. 99:933-936.

Toyoda, H., K. Shimizu, K. Chatani, N. Kita, Y. Matsuda, and S. Ouchi. 1989. Selection of bacterial wilt-resistant tomato through tissue culture. Plant Cell Rpt. 8:317-320.

Vales, M., T. Anzoátegui, B. Huallpa, and M.I. Cazon. 2018. Review on resistance to wheat blast disease (Magnaporthe oryzae Triticum) from the breeder point-of-view: Use of the experience on resistance to rice blast disease. Euphytica 214:1.

Van den Bulk, R.W. 1991. Application of cell and tissue culture and in vitro selection for disease resistance breeding: A review. Euphytica 56:269-285.

Vos, P., R. Hogers, M. Bleeker, M. Reijans, L.T. Van, M. Hornes, A. Frijters, J. Pot, J. Peleman, and M. Kuiper. 1995. AFLP: A new technique for DNA fingerprinting. Nucl. Acids Res. 23:4407-4414.

Wani, M.R., M.I. Kozgar, N. Tomlekova, S. Khan, A.G. Kazi, S.A. Sheikh, and P. Ahmad. 2014. Mutation breeding: A novel technique for genetic improvement of pulse crops particularly chickpea (Cicer arietinum L.), p. 217-248. In: P. Ahmad, M.R. Wani, M.M. Azooz, and L-.S.P. Lam (eds.). Improvement of crops in the era of climatic changes. Springer-Verlag, New York, NY.

Watanabe, S., T. Mizoguchi, K. Aoki, Y. Kubo, H. Mori, S. Imanishi, Y. Yamazaki, D. Shibata, and H. Ezura. 2007. Ethylmethanesulfonate (EMS) mutagenesis of Solanum lycopersicum cv. Micro-Tom for large-scale mutant screens. Plant Biotechnol. 24:33-38.

Williams, J.G.K., A.R. Kubelik, K.J. Livak, J.A. Rafalski, and S.V. Tingey. 1990. DNA polymorphisms amplified by arbitrary primers are useful as genetic markers. Nucl. Acids Res. 18:6531-6535.

Xu, L., H. Zhao, F. Ma, D. Liang, and E. Wan. 2007. Crude toxin isolated from Verturia noshicola on physiological characteristics of in vitro leaves of susceptible and resistant pear. Acta Botanica Boreali-Occidentalia Sinica 27:1156-1160 (in Chinese).

Yang, W., B. Tong, X. Zhang, G. Chen, Q. Gao, and X.U. Zhong. 2017. Influence on culture effect of several moulds of germination of potato PDA medium. Farm Prod. Processing 5:22-24 (in Chinese).

Yao, J.-C. 2014. Survey of major kalanchoe disease in northern Taiwan. Res. Rpt. Taoyuan Agr. Improvement Field 76:43-56 (in Taiwanese).

Yousefi, A.R. and F. Soheily. 2014. First report of Orobanche aegyptiaca on Kalanchoe blossfeldiana in Iran. Plant Dis. 98:1287. 